\title{
Cardioprotective effects of Dan-Yang-Fu-Xin decoction on chronic heart failure in rats
}

\author{
Jing-shu Guan ${ }^{1}$, Xiang Chen ${ }^{1}$ and Zheng-kun Yang ${ }^{2 *}$ \\ ${ }^{1}$ Department of Cardiology, Shuguang Hospital Baoshan Branch of Shanghai University of Traditional Chinese Medicine, \\ Shanghai, 201900, 'Department of Cardiology, Ruijin Hospital, Medical College, Shanghai Jiaotong University, Shanghai, \\ 312030, PR China
}

*For correspondence: Email: zhengkunyang123@163.com

\begin{abstract}
Purpose: To evaluate the cardioprotective effects and possible mechanisms of Dan-Yang-Fu-Xin decoction (DYFX) in a rat chronic heart failure (CHF).

Methods: A CHF rat model induced by ligation of the left anterior descending coronary artery was used to investigate the cardioprotective effects of DYFX. After intragastric administration for 8 weeks, several functional cardiac indices, including fractional shortening (FS), ejection fraction (EF), heart rate (HR) and cardiac output (CO) were assessed by ultrasound examination. Subsequently, inflammatory markers, viz, interleukin-6 (IL-6) and tumor necrosis factor- $\alpha$ (TNF-a), myocardial enzymes, namely, lactate dehydrogenase (LDH) and creatine kinase (CK), were also assessed by enzyme-linked immunosorbent assay (ELISA).

Results: Intragastric administration of DYFX (200, 400 and $600 \mathrm{mg} / \mathrm{kg})$ significantly reversed the decrease in body weight and increase in cardiac weight $(p<0.05)$ induced by CHF. Treatment with $D Y F X$ also significantly reversed EF, FS, HR, and CO changes in CHF rats. In addition, DYFX inhibited the two inflammatory cytokines (TNF- $\alpha$ and IL-6) and myocardial enzymes (CK and LDH), suggesting that these effects may include the mechanisms of cardioprotection involved in attenuation of CHF.

Conclusion: DYFX possesses cardioprotective effects involving CHF. The protective mechanisms may include the suppression of expression of inflammatory mediators and myocardial enzymes.
\end{abstract}

Keywords: Dan-Yang-Fu-Xin decoction, Cardioprotection, Chronic heart failure, Inflammatory mediators, Myocardial enzymes

Tropical Journal of Pharmaceutical Research is indexed by Science Citation Index (SciSearch), Scopus, International Pharmaceutical Abstract, Chemical Abstracts, Embase, Index Copernicus, EBSCO, African Index Medicus, JournalSeek, Journal Citation Reports/Science Edition, Directory of Open Access Journals (DOAJ), African Journal Online, Bioline International, Open-J-Gate and Pharmacy Abstracts

\section{INTRODUCTION}

Chronic heart failure (CHF) is a complex clinical syndrome involving impairment of cardiac pump function, resulting in a heart that cannot pump sufficient blood to meet the metabolic needs of the body [1,2]. CHF involves ventricular remodeling and hypertrophy, reduced cardiac ejection fractions (EFs) and impairment of active relaxation and contraction of the left ventricle [3]. CHF represents a major public health problem in the world because of its high morbidity, mortality and cost [4].

Currently, angiotensin receptor antagonists, $\beta$ blockers, mineralocorticoid receptor blockers and diuretics have been used for treatment of CHF. However, these treatments are because of their side effects including damage to the liver, kidney, and gastrointestinal tract [5,6]. Traditional Chinese medicine (TCM) has shown efficacy in treating complex multi-factor diseases, because 
TCM is a unique medical system that uses drugs with multiple components that have synergistic therapeutic efficacies [6-8]. Dan-Yang-Fu-Xin decoction (DYFX) is a TCM prescription consisting of Salvia miltiorrhiza, Epimedium brevicornu, Ligusticum wallichi, Astragalus membranaceus and Glycyrrhiza uralensis (Table 1).

It has been widely used in cities northern China, such as Linyi, Yanzhou and Tengzhou to treat coronary heart disease, anemia, chronic bronchitis and osteoporosis. DYFX is also beneficial for asthma and allergies. However, to the best of our knowledge, there have been no reports describing the pharmacological effects of DYFX.

The aim of the present study was to investigate the cardioprotective effects of DYFX in a CHF rat model by determining several cardiac function indices as well as the relationship between DYFX treatment and inflammatory markers.

\section{EXPERIMENTAL}

\section{Chemicals and reagents}

Interleukin-6 (IL-6) and tumor necrosis factor- $\alpha$ (TNF- $\alpha$ ) enzyme-linked immunosorbent assay (ELISA) kits were purchased from Shanghai Bluegene Biotech (Shanghai, China). Creatine kinase (CK) and lactate dehydrogenase (LDH) ELISA kits were purchased from R\&D systems (Beijing, China). Chloral hydrate was purchased from Kermel (Tianjin, China). All other chemicals and reagents used were of analytical grade.

\section{Preparation of DYFX water extracts}

Because DYFX is prepared by directly decocting with water in traditional folk medicine, all preparations of DYFX (Table 1) were in powder form and were soaked for $8 \mathrm{~h}$ before decocting with distilled water six times and extracted three times for $30 \mathrm{~min}$ each time. The decoction were filtered and concentrated under reduced pressure at $55{ }^{\circ} \mathrm{C}$ with a vacuum rotary evaporator. The resulting w/w yield of DYFX was $11.2 \%$. Distilled water was used to dissolve and dilute the extract to the appropriate concentrations for intragastric administration.

\section{CHF animal model}

Male Sprague-Dawley rats weighing $220 \pm 20 \mathrm{~g}$ were housed under controlled conditions at a temperature of $22 \pm 1^{\circ} \mathrm{C}$ and humidity of $45 \pm 5$ $\%$ with a $12 \mathrm{~h}$ light/dark cycle. The rats had free access to standard pallet diet (solid rodent chow) and tap water. The experiments were performed after 1 week acclimatization period. The experimental procedures were approved by the Committee of Animal Care and Use of our institute.

The rats were anaesthetized by intraperitoneal injection of chloral hydrate $(300 \mathrm{mg} / \mathrm{kg})$. Myocardial infarction and heart failure were induced by ligation of the left anterior descending coronary artery as previously described $[9,10]$. The surviving rats were randomly divided into five groups $(n=14)$ : 1$)$ the control group, 2$)$ the CHF group, 3 ) the high dose DYFX group (600 $\mathrm{mg} / \mathrm{kg} / \mathrm{d}), 4$ ) the medium dose DYFX group (400 $\mathrm{mg} / \mathrm{kg} / \mathrm{d}$ ), 5) the low dose DYFX group (200 $\mathrm{mg} / \mathrm{kg} / \mathrm{d}$ ). The control group received the same surgery but without ligating the vessel. The treatment was continued for 8 weeks via intragastric administration. At the end of the procedure, cardiac function was examined, blood samples were drawn from the abdominal aorta, and the serum was stored at $-80^{\circ} \mathrm{C}$.

\section{Determination of cardiac function}

Animals were anesthetized intraperitoneally with chloral hydrate $(300 \mathrm{mg} / \mathrm{kg})$. A portable ultrasound (Vivid I, GE Healthcare, Little Chalfont, UK) equipped with a $12-\mathrm{MHz}$ linear transducer $(12 \mathrm{~L})$ was used to determine the fractional shortening $(F S)$, ejection fraction $(E F)$, heart rate $(\mathrm{HR})$ and cardiac output (CO). An ultrasound image workstation (GE Healthcare) was used to transfer data online for subsequent analysis.

Table 1: Composition of Dan-Yang-Fu-Xin Decoction (DYFX)

\begin{tabular}{llc}
\hline Plant & Plant part & Weight (g) \\
\hline Salvia miltiorrhiza & Roots & 40 \\
Epimedium brevicornu & Whole herbs & 30 \\
Ligusticum wallichi & Roots & 15 \\
Astragalus membranaceus & Roots & 10 \\
Glycyrrhiza uralensis & Roots & 5 \\
\hline
\end{tabular}




\section{Determination of TNF- $\alpha$ and IL- 6}

The myocardial tissues were homogenized in RIPA lysis buffer containing $50 \mathrm{mM}$ Tris $-\mathrm{HCl}$ ( $\mathrm{pH}=7.4), 150 \mathrm{mM} \mathrm{NaCl}, 1 \%$ Triton X-100, $1 \%$ sodium deoxycholate, $0.1 \%$ SDS, $1 \mathrm{mM}$ $\mathrm{Na}_{3} \mathrm{VO}_{4}, \quad 1 \quad \mathrm{mM}$ EDTA, $1 \quad \mathrm{mM}$ phenylmethylsulfonyl fluoride and $1 \mathrm{mM} \mathrm{NaF}$, (myocardial tissue - RIPA lysis buffer ratio was = $1: 10, \mathrm{v} / \mathrm{v})$ and then centrifuged $(6,000 \times \mathrm{g}$, at 4 ${ }^{\circ} \mathrm{C}$ for $\left.15 \mathrm{~min}\right)$. The supernatants were collected to analyze TNF- $\alpha$ and IL- 6 using ELISA kits according to the manufacturers' instructions.

\section{Determination of serum LDH and CK}

Serum was separated from whole blood using centrifugation (6000 g, $4{ }^{\circ} \mathrm{C}$ and $15 \mathrm{~min}$ ). Serum levels of $\mathrm{LDH}$ and $\mathrm{CK}$ were measured using ELISA kits according to the manufacturer instructions.

\section{Statistical analysis}

Statistical analysis of data were performed using SPSS software, version 13.0 (SPSS, Chicago, IL, USA). All data are expressed as the mean \pm SD. One-way ANOVA was used for statistical analyses of observed values. A value of $p<0.05$ was considered statistically significant.

\section{RESULTS}

\section{Effects of DYFX on body weight and cardiac weight}

As shown in Table 2, the body weight of animals in the CHF group significantly decreased $(p<$ 0.05 ) compared with animals in control group. Furthermore, the whole heart weight, left ventricular weight, index of heart weight to body weight and index of left ventricle weight to body weight were significantly increased $(p<0.05)$ in $\mathrm{CHF}$ rats. However, intragastric administration of DYFX (200, 400, and $600 \mathrm{mg} / \mathrm{kg}$ ) significantly reversed these changes $(p<0.05)$, indicating that DYFX could reduce cardiac hypertrophy in CHF animals (Table 2).

\section{Effect of DYFX on cardiac functions}

Figure $1 \mathrm{~A}$ and $1 \mathrm{~B}$ showed that the EF and FS of the CHF group significantly decreased $(p<0.05)$ compared with the control group. However, the EF in DYFX treated groups increased significantly $(p<0.05)$ compared with the CHF group, and the FS in the DYFX treated groups $(400 \mathrm{mg} / \mathrm{kg}$ and $600 \mathrm{mg} / \mathrm{kg}, \quad p<0.05)$ significantly increased compared with the $\mathrm{CHF}$ group. $\mathrm{HR}$ and $\mathrm{CO}$ are shown in Figure $1 \mathrm{C}$ and 1D. The $\mathrm{HR}$ and $\mathrm{CO}$ of CHF rats were significantly decreased compared with the control group $(p<0.05)$. However, the HR in the DYFX treated groups significantly increased $(p<0.05)$ compared with the CHF group, and the $\mathrm{CO}$ in the DYFX treated groups (400 mg/kg and $600 \mathrm{mg} / \mathrm{kg}$, $p<0.05)$ significantly increased compared with the CHF group. Taken together, the results showed that DYFX significantly reversed EF, FS, $\mathrm{HR}$ and $\mathrm{CO}$ changes in CHF rats.

\section{Effect of DYFX on TNF- $\alpha$ and IL-6 levels}

Figure 2 shows that myocardial production of TNF- $\alpha$ and IL-6 increased significantly in the CHF group compared with the control group $(p<$ 0.01 ). The levels of the two cytokines decreased in groups treated with DYFX compared with the CHF group (200 mg/kg, $p<0.05 ; 400 \mathrm{mg} / \mathrm{kg}$ and $600 \mathrm{mg} / \mathrm{kg}, p<0.01$, respectively). The results showed that there was a close relationship between CHF and inflammation, and treatment with the DYFX effectively inhibited expression of the two inflammatory cytokines induced by CHF.

\section{Effect of DYFX on LDH and CK}

Figure 3 shows that, there was a significant increase $(p<0.01)$ in serum LDH levels of the CHF group compared with the control group. Treatment with $400 \mathrm{mg} / \mathrm{kg}$ DYFX resulted in a significant decrease $(p<0.01)$ in serum LDH levels as compared with the CHF group, and a significant increase $(p<0.01)$ in serum CK levels in the CHF groups compared with Control group.

Table 2: Effects of DYFX on body weight and cardiac weight

\begin{tabular}{llllll}
\hline Group & $\begin{array}{l}\text { Body weight } \\
(\mathbf{g})\end{array}$ & $\begin{array}{l}\text { Whole heart } \\
\text { weight } \mathbf{( g )}\end{array}$ & $\begin{array}{l}\text { Left ventricular } \\
\text { weight (g) }\end{array}$ & $\begin{array}{l}\text { Index of } \\
\text { Heartweight to } \\
\text { body weight }\end{array}$ & $\begin{array}{l}\text { Index of left } \\
\text { Heartweight to } \\
\text { body weight }\end{array}$ \\
\hline Control & $289.26 \pm 10.27^{*}$ & $0.86 \pm 0.09^{*}$ & $0.55 \pm 0.04^{*}$ & $0.30 \pm 0.03^{*}$ & $0.19 \pm 0.03^{*}$ \\
CHF & $268.75 \pm 8.53$ & $1.06 \pm 0.10$ & $0.78 \pm 0.08^{*}$ & $0.39 \pm 0.04$ & $0.29 \pm 0.02$ \\
200 & $279.32 \pm 9.76^{*}$ & $0.97 \pm 0.09$ & $0.63 \pm 0.06^{*}$ & $0.35 \pm 0.03$ & $0.23 \pm 0.03^{*}$ \\
400 & $284.72 \pm 8.92^{*}$ & $0.95 \pm 0.08^{*}$ & $0.59 \pm 0.05^{*}$ & $0.33 \pm 0.03^{*}$ & $0.21 \pm 0.02^{*}$ \\
600 & $283.91 \pm 7.98^{*}$ & $0.92 \pm 0.07^{*}$ & $0.58 \pm 0.03^{*}$ & $0.32 \pm 0.02^{*}$ & $0.20 \pm 0.02^{*}$ \\
\hline
\end{tabular}

Data were expressed as mean \pm SD; ${ }^{*} p<0.05$, compared with CHF group 

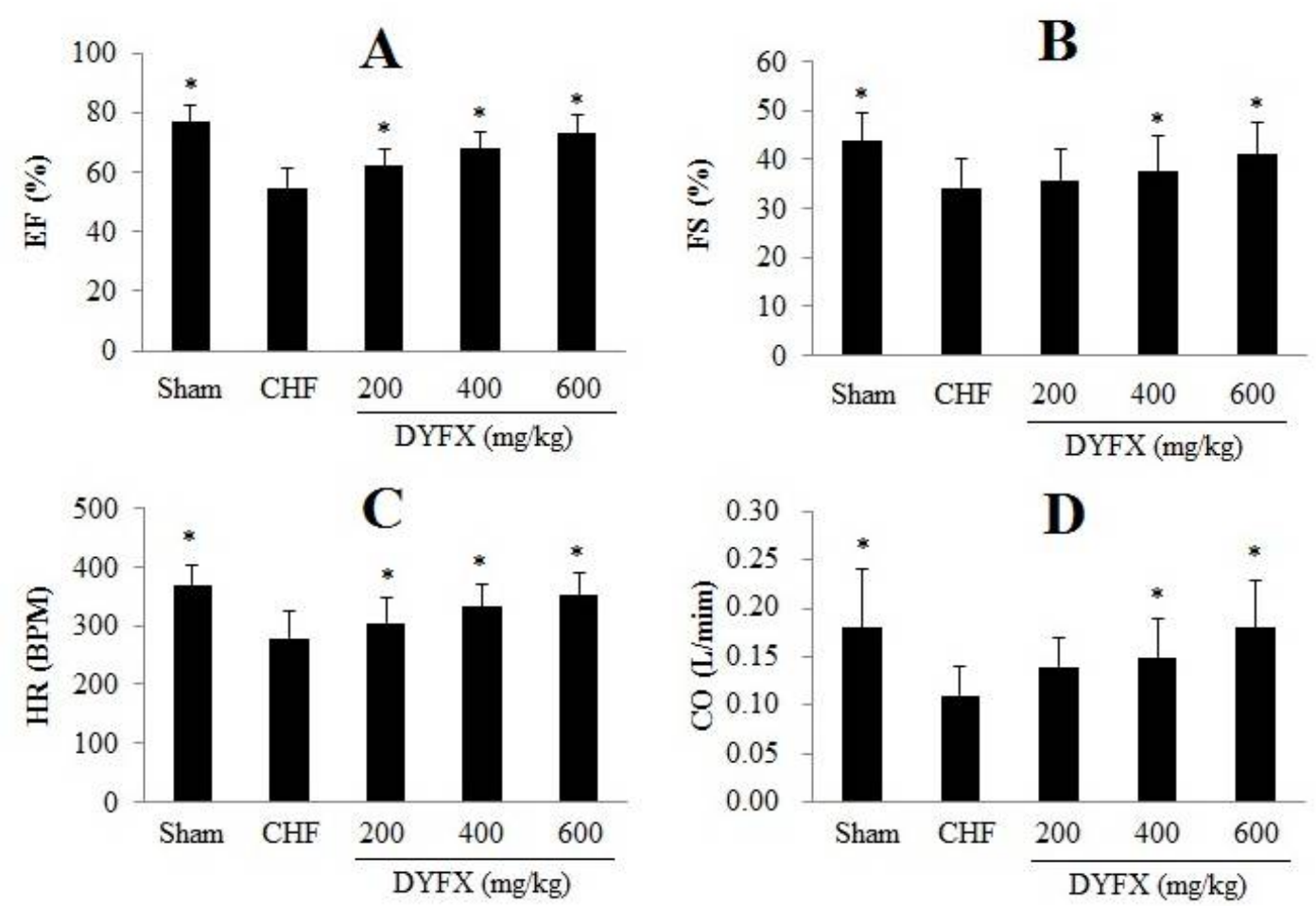

Figure 1: Effects of DYFX on EF, FS, CO and HR of the CHF rats. Data were expressed as Mean $\pm \mathrm{SD}$;. ${ }^{*} p<$ 0.05, compared with CHF group
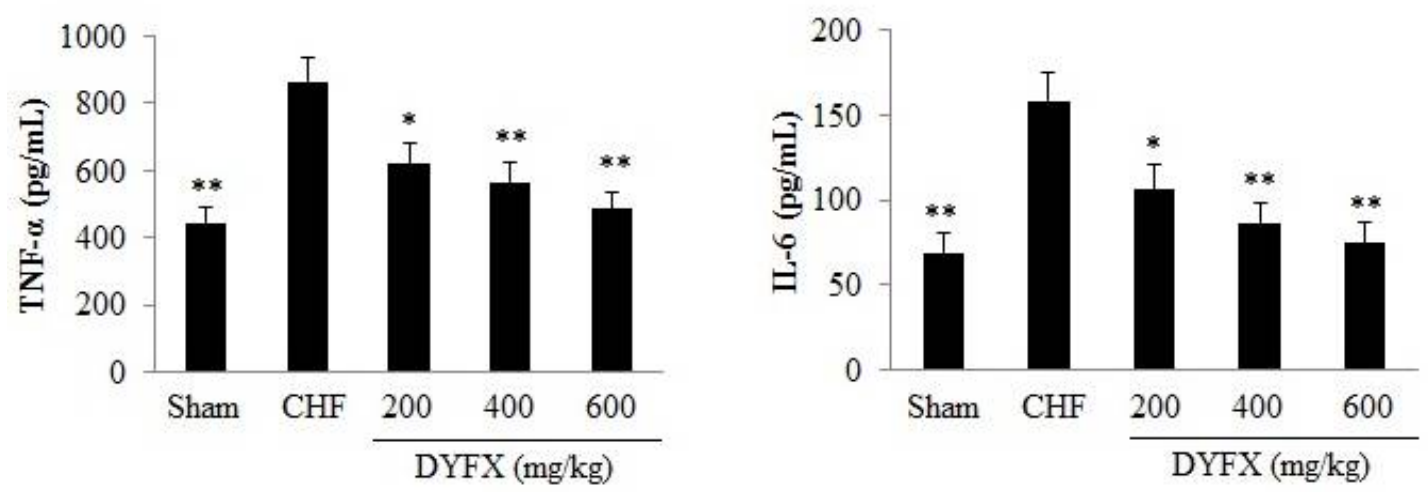

Figure 2: Effect of DYFX on TNF- $\alpha$, IL- 6 in CHF rats. Data were expressed as Mean \pm S.D.. ${ }^{*} p<0.05$, compared with CHF group. ${ }^{* *} p<0.01$, compared with CHF group
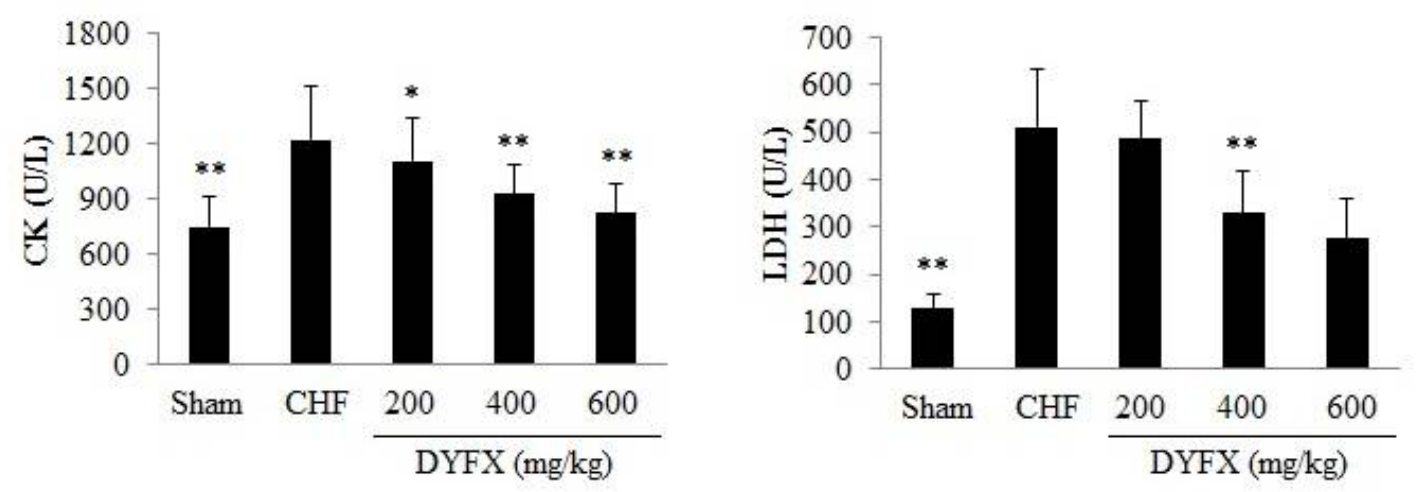

Figure 3: Effects of DYFX on CK and LDH in serum of CHF rats. Data were expressed as Mean \pm SD; * $p<0.05$, compared with $\mathrm{CHF}$ group; ${ }^{* *} p<0.01$, compared with $\mathrm{CHF}$ group 
Treatment $(200 \mathrm{mg} / \mathrm{kg}, p<0.05 ; 400 \mathrm{mg} / \mathrm{kg}$ and $600 \mathrm{mg} / \mathrm{kg}, p<0.01$ ) resulted in a significant decrease in serum CK levels compared with the CHF group.

\section{DISCUSSION}

In present study, a CHF rat model induced by ligation of the left anterior descending coronary artery was used to investigate the cardioprotective effects of DYFX. The results showed that DYFX reduced cardiac hypertrophy and reversed EF, FS, HR and $\mathrm{CO}$ changes in $\mathrm{CHF}$ rats. The possible mechanism of these cardioprotective effects might be related to the inhibition of inflammatory cytokine levels and myocardial enzymes levels. It is well-known that $\mathrm{CHF}$ is associated with immune activation, and its development and progression were closely related to inflammatory cytokines [11]. The overproduction of inflammatory factors, especially TNF- $\alpha$ and IL-6, could cause a decrease in cardiac systolic potential and cardiac output. The two factors could cause necrosis and apoptosis of cardiomyocytes and contribute to myocardial remodeling, resulting in worsening of CHF $[5,12]$. The levels of TNF- $\alpha$ and IL- 6 were evaluated in our study, showing that treatment with DYFX significantly suppressed the inflammation response via by decreasing the levels of TNF- $\alpha$ and IL- 6 in CHF rats.

CK and LDH are marker enzymes of cardiac damage. There have been many reports describing the relationship between the two myocardial enzymes and cardioprotective effects [13-15]. The CK and LDH are released into the blood stream after myocardial injury. These myocardial enzymes levels were determined in the serum of CHF rats in our study, showing that DYFX could decrease the levels of CK and LDH.

\section{CONCLUSION}

The present study shows that DYFX possesses potent cardioprotective effects on CHF animals. The protective mechanisms may involve suppression of the expressions of inflammatory mediators and myocardial enzymes. However, further investigations are required to identify the chemical constituents and complete mechanisms of DYFX action.

\section{CONFLICT OF INTEREST}

No conflict of interest associated with this work.

\section{CONTRIBUTION OF AUTHORS}

We declare that this work was done by the authors named in this article and all liabilities pertaining to claims relating to the content of this article will be borne by the authors.

\section{REFERENCES}

1. Doenst T, Nguyen TD, Abel ED. Cardiac metabolism in heart failure: implications beyond ATP production. Circ Res 2013; 113(6): 709-724.

2. Piper SE, Sherwood RA, Amin-Youssef GF, Shah AM, McDonagh TA. Serial soluble ST2 for the monitoring of pharmacologically optimised chronic stable heart failure. Int J Cardiol 2014; 178C: 284-291.

3. Zhang W, Zhang J, Kang Y, LiU J, Wang $X, X u$ Q, Wang $Y, X u X$, Dai G. Cardioprotective effects of oxymatrine on isoproterenol-induced heart failure via regulation of DDAH/ADMA metabolism pathway in rats. Eur $J$ Pharmacol 2014; 745C: 29-35.

4. Wu ZL, Ren H, Lai WY, Lin S, Jiang RY, Ye TC, Shen $Q B$, Zeng QC, Xu DL. Sclederma of Poria cocos exerts its diuretic effect via suppression of renal aquaporin-2 expression in rats with chronic heart failure. J Ethnopharmacol 2014; 155(1): 563-571.

5. Xing L, Jiang M, Dong L, Gao J, Hou Y, Bai G, Luo G. Cardioprotective effects of the YiQiFuMai injection and isolated compounds on attenuating chronic heart failure via NF-KB inactivation and cytokine suppression. J Ethnopharmacol 2013; 148(1): 239-245.

6. Guo $N$, Yang $D$, Wang $X$, Dai J, Wang $M$, Lei $Y$. Metabonomic study of chronic heart failure and effects of Chinese herbal decoction in rats. J Chromatogr $A$ 2014; 1362: 89-101.

7. Wang L, Zhou GB, Liu P, Song JH, Liang Y, Yan XJ, Xu $F$, Wang BS, Mao JH, Shen ZX, et al. Dissection of mechanisms of Chinese medicinal formula RealgarIndigo naturalis as an effective treatment for promyelocytic leukemia. Proc Natl Acad Sci USA 2008; 105(12): 4826-4831.

8. Chen $T, H u Y Q$, Deng $L R$, Gong $Z P, Y u X Q$. Effects of polysaccharides extracted from zhu zi shen (rhizoma panacis majoris) on oxidative stress and hemodynamics in rats with adriamycin-induced chronic heart failure. $J$ Tradit Chin Med 2011; 31(3): 235-240.

9. Gan XB, Sun HJ, Chen D, Zhang LL, Zhou $H$, Chen $L Y$, Zhou YB. Intermedin in the paraventricular nucleus attenuates cardiac sympathetic afferent reflex in chronic heart failure rats. PLoS One 2014; 9(4): e94234.

10. Swedberg K, Eneroth $P$, Kjekshus J, Wilhelmsen $L$. Hormones regulating cardiovascular function in patients with severe congestive heart failure and their relation to mortality. CONSENSUS Trial Study Group. Circulation 1990; 82(5): 1730-1736.

11. Batista ML Jr, Santos RV, Cunha LM, Mattos K, Oliveira $E M$, Seelaender MC, Costa Rosa LF. Changes in the 
pro-inflammatory cytokine production and peritoneal macrophage function in rats with chronic heart failure. Cytokine 2006; 34(5-6): 284-290.

12. Deswal A, Petersen NJ, Feldman AM, Young JB, White BG, Mann DL. Cytokines and cytokine receptors in advanced heart failure: an analysis of the cytokine database from the Vesnarinone trial (VEST). Circulation 2001; 103(16): 2055-2059.

13. El-Ani D, Zimlichman $R$, Mashiach $Y$, Shainberg $A$. Adenosine and TNF-alpha exert similar inotropic effect on heart cultures, suggesting a cardioprotective mechanism against hypoxia. Life Sci 2007; 81(10): 803813.
14. Thounaojam MC, Jadeja RN, Ansarullah, Karn SS, Shah JD, Patel DK, Salunke SP, Padate GS, Devkar RV, Ramachandran AV. Cardioprotective effect of Sida rhomboidea. Roxb extract against isoproterenol induced myocardial necrosis in rats. Exp Toxicol Pathol 2011; 63(4): 351-356.

15. Ishikawa $K$, Hashimoto $H$, Mitani S, Toki $Y$, Okumura $K$, Ito $T$. Enalapril improves heart failure induced by monocrotaline without reducing pulmonary hypertension in rats: roles of preserved myocardial creatine kinase and lactate dehydrogenase isoenzymes. Int $\mathrm{J}$ Cardiol 1995; 47(3): 225-233. 